\title{
Bowel movement frequency, oxidative stress and disease prevention (Review)
}

\author{
ALPHONS J.M. VERMORKEN ${ }^{1,2}$, EMMANUEL ANDRÈS ${ }^{3}$ and YALI CUI ${ }^{1,2}$ \\ ${ }^{1}$ College of Life Sciences, Northwest University; ${ }^{2}$ National Engineering Research Center for Miniaturized Detection Systems, \\ Xi'an, Shaanxi 710069, P.R. China; ${ }^{3}$ Department of Internal Medicine, Diabetes and Metabolic Disorders, \\ University Hospital of Strasbourg, 67091 Strasbourg, France
}

Received April 19, 2016; Accepted June 27, 2016

DOI: $10.3892 /$ mco. 2016.987

\begin{abstract}
The significance of diet for disease prevention has long been recognised. Dietary recommendations have therefore been integrated in health promotion messages. Gastrointestinal functioning is essential for the digestion of nutrients. Oxidative stress has been observed in patients with constipation, as well as in those with colorectal cancer, cardiovascular disease and other chronic illnesses associated with constipation. The coexistence of colorectal neoplasia and coronary artery disease has been incriminated for exposure to common risk factors associated with increased oxidative stress. It was recently demonstrated that bowel movement frequency is inversely associated with cardiovascular mortality. The aim of the present study was to review the relevant literature in light of these findings. It was concluded that suboptimal functioning of the large bowel may contribute to oxidative stress and, therefore, to increased mortality. Bowel movement frequency may represent a simple quantifiable indicator of adequate colonic function and it is dependent on diet, exercise and other lifestyle factors, but also on individual characteristics, including colonic microbiota. Future health promotion actions may improve the prevention of a number of diseases by advocating lifestyle personalisation for assuring optimal intestinal functioning.
\end{abstract}

\section{Contents}

1. Introduction

2. Rationale

3. Conclusion

Correspondence to: Professor Alphons J.M. Vermorken, College of Life Sciences, Northwest University, 229 Taibai North Road, Xi'an, Shaanxi 710069, P.R. China

E-mail: fons@nwu.edu.cn

Key words: constipation, colorectal cancer, cardiovascular mortality, chronic diseases, oxidative stress, butyric acid, 5'-adenosine monophosphate-activated protein kinase, Mediterranean diet, bowel function, microbiota

\section{Introduction}

Dietary habits significantly affect the incidence of colorectal cancer, cardiovascular disease and other chronic illnesses. The high prevalence of colonic polyps among patients hospitalized for coronary artery disease is considered to be due to shared underlying risk factors, i.e., old age, male gender, diabetes, hyperlipidemia, smoking history and high body mass index (1). All these risk factors have been associated with increased oxidative stress. Solid evidence has been obtained regarding the nature of diets preventing cardiovascular events (2). A comparison of the Mediterranean diet and less well-known diets, also associated with a decreased risk of cardiovascular events, revealed several shared characteristics: High intake of unrefined carbohydrates, moderate protein intake with emphasis on vegetables/legumes, fish and lean meats as the sources, and a healthy fat profile, higher in mono/polyunsaturated fats, lower in saturated fat and rich in omega-3 fatty acids (3). These diets are plant-rich, suggesting that fibres and resistant starch play important roles $(4,5)$. All diets result in a low glycemic load, less oxidative stress and less inflammation (3). The impact of these dietary characteristics on public health is already important regarding prevention of cardiovascular disease. Adherence to the Mediterranean diet reduces cardiovascular events to a degree greater than low-fat diets and, importantly, equal to or greater than the benefit observed in statin trials (6). Dietary recommendations for disease prevention have therefore been integrated in health promotion messages.

As diet is important for disease prevention, so is intact gastrointestinal function. The mechanisms controlling gastrointestinal function are numerous and complex. Simple quantifiable indicators of adequate function associated with prevention of chronic diseases were not previously available. However, the recently published 13-year study of Honkura et al provides evidence supporting an association of self-reported defecation frequency with cardiovascular mortality (7). Integrating the significance of daily bowel movements in health promotion messages may therefore be in the public interest.

\section{Rationale}

Since the 1970s it has been suggested that dietary fibre may help prevent colorectal cancer and cardiovascular disease by 
affecting the bacterial flora and physiological processes in the gut (8). An increased fibre intake shortens the orocecal transit time, which was considered to affect the risk for colorectal cancer and cardiovascular disease, as well as other diseases (8). A meta-analysis of risk factors for colorectal cancer in China identified dietary fibre intake as protective (9). A recent systematic review and meta-analysis confirmed that an increased intake of total dietary fibre is associated with a lower risk of cardiovascular disease in healthy populations (4). Dietary modifications affect the number and types of gut bacteria and their metabolic activity (10). However, individuals with identical dietary intakes may exhibit a threefold difference in transit times (11).

Further research was therefore focused on the effect of pharmacologically manipulating the transit time on energy production in the colon with equal dietary intake $(12,13)$. Slowing down transit reduced the fermentation efficacy of complex carbohydrates and led to a diminished production of the short-chain fatty acids (SCFAs), acetic acid, propionic acid and butyric acid, of which butyric acid is an energy source for colonocytes and for the host. However, accelerating transit increased energy production (12). Approximately twice as much butyric acid was produced in the fast-transit compared with that in the slow-transit group. The ratio between acetic acid and propionic acid was also roughly two times higher in the slow-transit group. Decreasing the acetate/propionate ratio may reduce serum lipids and, therefore, possibly cardiovascular disease risk (14). Individual differences in the molar ratios and concentrations of acetate and propionate and concentrations of butyrate in the feces were reported to remain constant, at least over a period of $>3$ years (15).

Severe constipation, often accompanied by slower transit, was found to be associated with cardiovascular risk, at least in post-menopausal women (16). The association of constipation with colorectal cancer is controversial $(17,18)$. However, a recent study involving $\sim 29,000$ patients with chronic constipation and $>86,000$ controls reported that chronic constipation is associated with a significantly higher prevalence and incidence of colorectal cancer and benign colorectal neoplasms compared with those in matched chronic constipation-free individuals. These risks increase with the severity of chronic constipation (19). Chronic constipation is caused by a variety of factors (20); however, it is difficult to quantify and, therefore, less convenient as an indicator of cancer or cardiovascular risk. The data of Honkura et al (7) demonstrated that bowel movement frequency may be a promising indicator for public health purposes. It is therefore relevant to reflect on the mechanism(s) underlying the association of defecation frequency with disease risk.

Butyrate provides energy for colonocytes. Colonising germ-free animals with gut bacteria allows the animals to harvest otherwise inaccessible nutrients (21). As a result, the NADH/NAD ${ }^{+}$ratio and the ATP levels in their colon increase (22). Energy deficiency in colonocytes leads to a decrease in cellular oxidative phosphorylation, with oxidative stress as a result (23). In an attempt to maintain energy homeostasis, 5'-adenosine monophosphate-activated protein kinase, a sensor that is activated by decreasing ATP levels (24), induces autophagy in the colonocytes (22). Butyrate, following beta oxidation to acetyl-CoA, enters the tricarboxylic acid cycle. This leads to the reduction of $\mathrm{NAD}^{+}$to $\mathrm{NADH}$, which enters the electron transport chain, resulting in the formation of ATP and $\mathrm{CO}_{2}$ (22) and diminishing autophagy and oxidative stress.

The fecal stream is crucial for the integrity of the colonic mucosa. Following surgical diversion of part of the intestine, luminal concentrations of SCFAs are significantly reduced in the bypassed part of the intestine (25). Colonic segments without a fecal stream exhibit high levels of oxidative DNA damage, which increases with the time of intestinal exclusion (26). Enemas with the antioxidant $\mathrm{N}$-acetylcysteine significantly reduce oxidative DNA damage in colonic segments without a fecal stream (27). Dietary resistant starch increased SCFAs and reduced inflammation and cell proliferation in a rat colitis-associated colorectal cancer model (28). The SCFAs may represent only one of the factors involved in reducing oxidative stress. The Mediterranean diet contains more macromolecular antioxidants compared with the low-molecular weight or soluble antioxidants usually taken into account (29). Macromolecular antioxidants are only released during the process of colonic fermentation (30); they may also reduce oxidative stress and they play a role in maintaining the luminal reductive environment, protecting the growth of anaerobic microbiota (31).

Several mechanisms have been proposed above to explain how accelerating transit and avoiding constipation reduces oxidative stress. However, it remains unclear whether the cumulative effect is of a sufficient magnitude to prevent cardiovascular disease. Chronic kidney disease is characterized by oxidative stress and increased incidence of cardiovascular mortality $(32,33)$. In a rat model of chronic kidney disease, a high amylose-resistant starch diet was shown to ameliorate oxidative stress, inflammation and progression of chronic kidney disease (34). The Mediterranean plant-rich diet favours the prevalence of saccharolytic species among gut microbiota, whereas the Western meat-rich diet promotes a shift towards a proteolytic profile, causing dysbiosis (35). The gut microbiota thus forms a plausible link between adherence to the Mediterranean diet, reduced oxidative stress and decreased loss of kidney function $(35,36)$. Oxidative stress plays a role in the etiopathogenesis of several diseases associated with constipation (37). Oxidative stress leads to intestinal dysmotility, creating a vicious cycle $(38,39)$. The intestinal microbiota may therefore have the potential to significantly affect oxidative stress and the progression of all the constipation-associated diseases in the host. Two independent population-based studies reported that chronic constipation is associated with increased mortality $(40,41)$. The key issue is whether the alleviation of constipation reduces oxidative stress and the risk for the associated diseases; there is evidence that this may be the case (37). In an animal model, inducing constipation led to oxidative stress, whereas prebiotics attenuated both constipation and oxidative stress (42). Prolonged duration of constipation in children was found to lead to oxidative stress (43) and growth retardation (44), whereas effective management of constipation attenuated the growth retardation (44). Consequently, assuring proper bowel movement frequency may significantly affect public health.

Surprisingly, defecation frequency was only poorly correlated with whole-gut and colonic transit times $(45,46)$. A more 
regular fecal flow associated with more frequent bowel movements may, besides the transit pace, be an additional factor increasing the efficacy of the fermentation process and its effect on oxidative stress. This is a plausible hypothesis, but remains to be confirmed in future studies. In this context, it may be of interest to include defecation frequency as a parameter, independent of solids retention time, in a recent in silico model of colonic fermentation (47).

\section{Conclusion}

Several chronic diseases, including certain types of cancer, metabolic syndrome and diabetes, share common behavioural risk factors with colorectal cancer and cardiovascular disease. These include: Active and passive smoking, being overweight, a sedentary lifestyle, an unhealthy diet and more than occasional alcohol consumption. Oxidative stress plays a role in the etiopathogenesis of these diseases and is associated with the abovementioned behavioural risk factors. The global epidemic of cardiovascular and other chronic diseases is still evolving, including in China (48). A number of organizations focused on these chronic diseases aim at jointly supporting approaches for the reduction of shared risk factors, while at the same time retaining disease-specific programs (49). Once the results of Honkura et al (7) are independently confirmed, global actors for this set of diseases may maximize their efforts by integrating the significance of daily bowel movements into future concerted health promotion messages and actions. This could be vital for success of disease prevention and reduction of mortality.

\section{References}

1. Chan AO, Jim MH, Lam KF, Morris JS, Siu DC, Tong T, Ng FH, Wong SY, Hui WM, Chan CK, et al: Prevalence of colorectal neoplasm among patients with newly diagnosed coronary artery disease. JAMA 298: 1412-1419, 2007.

2. Grosso G, Marventano S, Yang J, Micek A, Pajak A, Scalfi L, Galvano F and Kales SN: A comprehensive meta-analysis on evidence of mediterranean diet and cardiovascular disease: Are individual components equal? Crit Rev Food Sci Nutr: 0, 2015.

3. Willcox DC, Scapagnini G and Willcox BJ: Healthy aging diets other than the Mediterranean: A focus on the Okinawan diet. Mech Ageing Dev 136-137: 148-162, 2014.

4. Threapleton DE, Greenwood DC, Evans CE, Cleghorn CL, Nykjaer C, Woodhead C, Cade JE, Gale CP and Burley VJ: Dietary fibre intake and risk of cardiovascular disease: Systematic review and meta-analysis. BMJ 347: f6879, 2013.

5. Slavin JL: Carbohydrates, dietary fiber, and resistant starch in white vegetables: Links to health outcomes. Adv Nutr 4: 351S-355S, 2013.

6. Dalen JE and Devries S: Diets to prevent coronary heart disease 1957-2013: What have we learned? Am J Med 127: 364-369, 2014.

7. Honkura K, Tomata Y, Sugiyama K, Kaiho Y, Watanabe T, Zhang S, Sugawara Y and Tsuji I: Defecation frequency and cardiovascular disease mortality in Japan: The Ohsaki cohort study. Atherosclerosis 246: 251-256, 2016.

8. Burkitt DP, Walker AR and Painter NS: Effect of dietary fibre on stools and the transit-times, and its role in the causation of disease. Lancet 2: 1408-1412, 1972.

9. Chen K, Qiu JL, Zhang Y and Zhao YW: Meta-analysis of risk factors for colorectal cancer. World J Gastroenterol 9: 1598-1600, 2003.

10. Rowland IR, Mallett AK and Wise A: The effect of diet on the mammalian gut flora and its metabolic activities. Crit Rev Toxicol 16: 31-103, 1985.

11. Stephen AM, Wiggins HS and Cummings JH: Effect of changing transit time on colonic microbial metabolism in man. Gut 28: 601-609, 1987.
12. El Oufir L, Flourié B, Bruley des Varannes S, Barry JL, Cloarec D, Bornet F and Galmiche JP: Relations between transit time, fermentation products, and hydrogen consuming flora in healthy humans. Gut 38: 870-877, 1996.

13. Lewis SJ and Heaton KW: Increasing butyrate concentration in the distal colon by accelerating intestinal transit. Gut 41: 245-251, 1997.

14. Wong JM, de Souza R, Kendall CW, Emam A and Jenkins DJ: Colonic health: Fermentation and short chain fatty acids. J Clin Gastroenterol 40: 235-243, 2006.

15. Weaver GA, Krause JA, Miller TL and Wolin MJ: Constancy of glucose and starch fermentations by two different human faecal microbial communities. Gut 30: 19-25, 1989.

16. Salmoirago-Blotcher E, Crawford S, Jackson E, Ockene J and Ockene I: Constipation and risk of cardiovascular disease among postmenopausal women. Am J Med 124: 714-723, 2011.

17. Tashiro N, Budhathoki S, Ohnaka K, Toyomura K, Kono S, Ueki T, Tanaka M, Kakeji Y, Maehara Y, Okamura T, et al: Constipation and colorectal cancer risk: The fukuoka colorectal cancer study. Asian Pac J Cancer Prev 12: 2025-2030, 2011.

18. Power AM, Talley NJ and Ford AC: Association between constipation and colorectal cancer: Systematic review and meta-analysis of observational studies. Am J Gastroenterol 108: 894-903, 2013.

19. Guérin A, Mody R, Fok B, Lasch KL, Zhou Z, Wu EQ, Zhou W and Talley NJ: Risk of developing colorectal cancer and benign colorectal neoplasm in patients with chronic constipation. Aliment Pharmacol Ther 40: 83-92, 2014.

20. Andrews CN and Storr M: The pathophysiology of chronic constipation. Can J Gastroenterol 25 (Suppl B): 16B-21B, 2011.

21. Bäckhed F, Ding H, Wang T, Hooper LV, Koh GY, Nagy A, Semenkovich $\mathrm{CF}$ and Gordon JI: The gut microbiota as an environmental factor that regulates fat storage. Proc Natl Acad Sci USA 101: 15718-15723, 2004.

22. Donohoe DR, Garge N, Zhang X, Sun W, O'Connell TM, Bunger MK and Bultman SJ: The microbiome and butyrate regulate energy metabolism and autophagy in the mammalian colon. Cell Metab 13: 517-526, 2011.

23. Harty RF: Energy, oxidative stress, and inflammation in the colon. Dig Dis Sci 58: 3386-3388, 2013.

24. Shaw RJ, Kosmatka M, Bardeesy N, Hurley RL, Witters LA, DePinho RA and Cantley LC: The tumor suppressor LKB1 kinase directly activates AMP-activated kinase and regulates apoptosis in response to energy stress. Proc Natl Acad Sci USA 101: 3329-3335, 2004.

25. Harig JM, Soergel KH, Komorowski RA and Wood CM: Treatment of diversion colitis with short-chain-fatty acid irrigation. N Engl J Med 320: 23-28, 1989.

26. Martinez CA, Ribeiro ML, Gambero A, Miranda DD, Pereira JA and Nadal SR: The importance of oxygen free radicals in the etiopathogenesis of diversion colitis in rats. Acta Cir Bras 25: 387-395, 2010.

27. Martinez CA, de Almeida MG, da Silva CM, Ribeiro ML, da Cunha FL, Rodrigues MR, Sato DT and Pereira JA: Enemas with $\mathrm{N}$-acetylcysteine can reduce the level of oxidative damage in cells of the colonic mucosa diverted from the faecal stream. Dig Dis Sci 58: 3452-3459, 2013.

28. Hu Y, Le Leu RK, Christophersen CT, Somashekar R, Conlon MA, Meng XQ, Winter JM, Woodman RJ, McKinnon R and Young GP: Manipulation of the gut microbiota using resistant starch is associated with protection against colitis-associated colorectal cancer in rats. Carcinogenesis 37: 366-375, 2016

29. Pérez-Jiménez J, Díaz-Rubio ME and Saura-Calixto F: Contribution of macromolecular antioxidants to dietary antioxidant capacity: A Study in the Spanish Mediterranean Diet. Plant Foods Hum Nutr 70: 365-70, 2015.

30. Tabernero M, Venema K, Maathuis AJ and Saura-Calixto FD: Metabolite production during in vitro colonic fermentation of dietary fiber: Analysis and comparison of two European diets. J Agric Food Chem 59: 8968-8975, 2011.

31. La Scola B, Khelaifia S, Lagier JC and Raoult D: Aerobic culture of anaerobic bacteria using antioxidants: A preliminary report. Eur J Clin Microbiol Infect Dis 33: 1781-1783, 2014.

32. Ma Y, Zhou L, Dong J, Zhang X and Yan S: Arterial stiffness and increased cardiovascular risk in chronic kidney disease. Int Urol Nephrol 47: 1157-1164, 2015.

33. Ohno Y, Kanno Y and Takenaka T: Central blood pressure and chronic kidney disease. World J Nephrol 5: 90-100, 2016. 
34. Vaziri ND, Liu SM, Lau WL, Khazaeli M, Nazertehrani S, Farzaneh SH, Kieffer DA, Adams SH and Martin RJ: High amylose resistant starch diet ameliorates oxidative stress, inflammation, and progression of chronic kidney disease. PLoS One 9: e114881, 2014.

35. Montemurno E, Cosola C, Dalfino G, Daidone G, De Angelis M, Gobbetti M and Gesualdo L: What would you like to eat, Mr CKD Microbiota? A Mediterranean Diet, please! Kidney Blood Press Res 39: 114-123, 2014.

36. Khatri M, Moon YP, Scarmeas N, Gu Y, Gardener H, Cheung K, Wright CB, Sacco RL, Nickolas TL and Elkind MS: The association between a Mediterranean-style diet and kidney function in the Northern Manhattan Study cohort. Clin J Am Soc Nephrol 9: $1868-1875,2014$

37. Vermorken A, Andrès E and Cui Y: Chronic constipation-a warning sign for oxidative stress? Aliment Pharmacol Ther 42 : 385-386, 2015.

38. Kashyap P and Farrugia G: Oxidative stress: Key player in gastrointestinal complications of diabetes. Neurogastroenterol Motil 23: $111-114,2011$

39. Talley NJ: Letter: Chronic constipation-a warning sign for oxidative stress? Author's reply. Aliment Pharmacol Ther 42: 386 , 2015.

40. Koloski NA, Jones M, Wai R, Gill RS, Byles J and Talley NJ: Impact of persistent constipation on health-related quality of life and mortality in older community-dwelling women. Am J Gastroenterol 108: 1152-1158, 2013.

41. Chang JY, Locke GR III, McNally MA, Halder SL, Schleck CD, Zinsmeister AR and Talley NJ: Impact of functional gastrointestinal disorders on survival in the community. Am J Gastroenterol 105 822-832, 2010.
42. Li Y, Zong Y, Qi J and Liu K: Prebiotics and oxidative stress in constipated rats. J Pediatr Gastroenterol Nutr 53: 447-452, 2011

43. Zhou JF, Lou JG, Zhou SL and Wang JY: Potential oxidative stress in children with chronic constipation. World J Gastroenterol 11: 368-371, 2005.

44. Chao HC, Chen SY, Chen CC, Chang KW, Kong MS, Lai MW and Chiu CH: The impact of constipation on growth in children. Pediatr Res 64: 308-311, 2008.

45. Saad RJ, Rao SS, Koch KL, Kuo B, Parkman HP, McCallum RW, Sitrin MD, Wilding GE, Semler JR and Chey WD: Do stool form and frequency correlate with whole-gut and colonic transit? Results from a multicenter study in constipated individuals and healthy controls. Am J Gastroenterol 105: 403-411, 2010

46. de Vries J, Miller PE and Verbeke K: Effects of cereal fiber on bowel function: A systematic review of intervention trials. World J Gastroenterol 21: 8952-8963, 2015.

47. Motelica-Wagenaar AM, Nauta A, van den Heuvel EG and Kleerebezem R: Flux analysis of the human proximal colon using anaerobic digestion model 1. Anaerobe 28: 137-148, 2014. 48. Zheng Y, Stein R, Kwan T, Yu C, Kwan J, Chen SL and Hu D Evolving cardiovascular disease prevalence, mortality, risk factors, and the metabolic syndrome in China. Clin Cardiol 32: 491-497, 2009.

49. Promoting Cardiovascular Health in the Developing World: A Critical Challenge to Achieve Global Health. Institute of Medicine (US) Committee on Preventing the Global Epidemic of Cardiovascular Disease: Meeting the Challenges in Developing Countries; Fuster V, Kelly BB, editors. Washington (DC): National Academies Press (US); 2010. ISBN-13: 978-0-309-14774-3, ISBN-10: 0-309-14774-3. 